Macías Lara, Tamara.

Graduada en Conservación y Restauración de Bienes Culturales por la UPV.

Técnica Superior en desarrollo y aplicación de proyectos de construcción por la UPV.

Zalbidea Muñoz, María Antonia.

Profesora de la UPV. Departamento de Conservación y Restauración de Bienes Culturales.

\title{
Puesta en valor del muralismo contemporáneo de Blu en la ciudad de Valencia.
}

\section{The assessment the contemporary muralism of Blu in the city of Valencia.}

\author{
TIPO DE TRABAJO: \\ Comunicación. \\ PALABRAS CLAVE: \\ Muralismo contemporáneo, Conservación, Blu, Valencia, Street Art. \\ KEY WORDS: \\ Contemporary muralism, Conservation, Blu, Valencia, Street Art.
}

RESUMEN.

El trabajo que se desarrolla emerge con la finalidad de estudiar la posibilidad de conservación del mural realizado en 2011 por el artista italiano Blu, uno de los mayores exponentes internacionales de arte urbano. Dicha obra se sitúa en la medianera de la plaza del Tossal, lindando con el número 5 de la Calle Quart en Valencia.

El tema de estudio genera controversia en la distinción de su reconocimiento como arte, los conservadores se hallan en complejas tesituras condicionadas por cuestiones legales, por arduas tomas de decisiones e incluso por otros componentes ajenos a la conservación.

\begin{abstract}
He ahí, tal vez, la polémica sobre el reconocimiento, la legitimidad y la propiedad de las intervenciones. Simultáneamente, el uso de materiales modernos, su ejecución y la inexistente y/o inadecuada preparación del soporte acelera el deterioro de su estado. Resaltando la dificultad que supone tanto la intervención, como la conservación; y la importancia que tiene la documentación fotográfica en estas intervenciones artísticas.

En vista de ello, ha sido necesario un estudio profundo de la obra mediante examen científico de la materia constitutiva y la técnica de ejecución, así como el análisis formal y conceptual de la misma, antecedido por su contexto histórico-artístico. Mediante examen organoléptico se ha determinado las patologías que presenta el mural trazando un estudio de su estado de conservación de la obra.

En resumen y por estas razones, nace la necesidad de estudiar y analizar la obra del ya consagrado muralista contemporáneo y referente para el Street Art, Blu.
\end{abstract}




\section{ABSTRACT.}

This work that emerges with the purpose of studying the possibility of conservation of the mural realized in 2011 by the Italian artist Blu, one of the greatest international exponents of urban art. This mural painting is located in the middle of the Plaza del Tossal, bordering 5 Quart Street in Valencia.

The subject of study generates controversy in the distinction of its recognition like art, the conservatives are in complex position conditioned by legal questions, by arduous decision-making and even by other non-conservation components. There is, perhaps, the controversy over the recognition, legitimacy and ownership of interventions.

Simultaneously, the use of modern materials, their execution and the ineffective or inadequate preparation of the support accelerates the deterioration of their state. Highlighting the difficulty of intervention and conservation; And the importance of photographic documentation in these artistic interventions.

In view of this, an in-depth study of the work has been necessary through scientific examination of the constitutive material and the technique of execution, as well as the formal and conceptual analysis of the work, preceded by its historical-artistic context; Through organoleptic examination has determined the pathologies presented by the mural drawing a study of its current state. Finally, we conclude with the elaboration of a proposal for intervention, and in the same way, we propose some guidelines for conservation of the artwork.

In summary and for these reasons, the need arises to study and analyze the work of the already consecrated contemporary muralist and great influence for the Street Art, Blu.

\section{CONTENIDO.}

\section{BLU, ARTISTA URBANO.}

Bajo el pseudónimo de Blu, este artista italiano ha contribuido a dar forma al arte urbano, decide permanecer en el anonimato y empieza a ser conocido en la escena del arte urbano a partir del 1999 con motivo de la realización de unos graffitis en el centro histórico y suburbios de Bolonia. Sus obras reflejan y representan las características de dicho movimiento evidenciando algunos de sus signos distintivos: la reivindicación del espacio público, el efecto sorpresa y finalmente, la voluntad de comunicar mensajes. Su labrada reputación mundial, le presenta como uno de los mejores artistas urbanos en circulación, con gran impacto mediático como acredita el diario británico The Guardian ${ }^{1}$, que en agosto del 2011, clasifica al muralista entre los diez mejores artistas urbanos del mundo, entre ellos, el diario incluye también a Jenny Holzer, Keith Haring, Steve Powers, JR, Os Gêmeos, Vhils, Banksy, y Sam Swoon.

Son muy diferentes los contextos en los que Blu realiza sus murales, puesto que aparecen en lugares anónimos o lugares emblemáticos (dado su consagrada fama mundial), y siempre dentro de los términos legales. Siendo contratado por instituciones, festivales culturales ${ }^{2}$, museos (como el MOCA -The Museum of Contemporary Art, Los Ángeles) o exposiciones relacionadas con el arte urbano donde sus enormes figuras de humanoides y sarcásticas o dramáticas escenas dibujadas e inspiradas en el mundo de los cómics y juegos de Arcade, mezclan además el sentido de aventura con la rutina urbana, la invención personal y las grandes cuestiones colectivas. En sus primeros murales, al tiempo que expresaba y desarrollaba elementos de gran originalidad estilística, estaban creados con spray (pintura en aerosol). Desde el año 2001 las obras de Blu comienzan a verse como pinturas plásticas ya que pronto incorpora el uso de la brocha y de rodillos montados en postes telescópicos. Esta técnica le permite realizar murales a gran escala a la vez que reducir costes. Blu traza las figuras perfiladas en sólidos contornos negros y dos colores como máximo, no firma, pero no hace falta sus obras ya que su obra tiene un singular sello de identidad.

En la entrevista que otorgó en 2004 para la Web Fatbombers recoge muchas de sus opiniones e impresiones, de hecho, en ellas se afirma que: "...nunca pensé en hacer..." obras de arte "...difíciles de vender en el mercado del arte...", "Cada dibujo que pinto expresa un pensamiento, así sucede que, mis personajes apuntan a temas sociales; causa muy a menudo de lo que pienso de nuestra loca sociedad...", "En cuanto a la expresión de un pensamiento político, creo que eso es algo que naturalmente ocurre cada vez que pinto una pared. El hecho en sí de que tu estés pintando es la expresión de un pensamiento." "No confundir un pensamiento político con una

\footnotetext{
${ }^{1}$ MANCO, Tristán. The 10 best street art Works. En: The Guardian. [Consulta 27/02/2017] Publicado: 6 agosto 2011. Disponible en: https://www.theguardian.com/culture/gallery/2011/aug/07/art

${ }^{2}$ Fue premiado en 2009 en el Festival Internacional de cortometraje de Clermont-Ferrand.
} 
ideología preconcebida, no estoy interesado en hacer propaganda a favor de un partido político, no estoy dibujando guadañas y martillos, ni cruces celtas. No confío en los políticos títeres que gobiernan nuestros países" ${ }^{\prime 3}$.

Su obra ha sido premiada en diversos festivales y aunque su intención no es la de buscar la visibilidad mediática, Blu, fue uno de los protagonistas de una clamorosa acción en las navidades del 2007 conocida como el "ataque simbólico", que tuvo lugar en el muro que el gobierno israelí construyó (en Belén) para aislar los territorios palestinos. No exento de polémica volvió a ser noticia en 2014 por cubrir dos de sus míticas obras en el distrito de Kreuzberg de Berlín con la intención de evitar que una inmobiliaria mercantilizase y se lucrase intencionadamente de sus intervenciones; siguiendo el mismo modus operandi, Blu, en 2016 funde en negro todas sus piezas de las calles de la ciudad de Bolonia como protesta a los arranques que habían sufrido algunas de sus obras y que posteriormente fueron trasladadas al museo de la ciudad para la exposición Street Art Banksy \& Co. L'arte allo stato urbano, descontextualizándolas de sus emplazamientos originales para ser embutidas en un entorno ajeno para el cual no fue creada. Como sostiene Doerner, la pintura mural "Es una pintura que no depende sólo de ella exclusivamente, sino de la arquitectura que la rodea y del color y forma de los espacios inmediatos ${ }^{4 \prime}$

\section{MOISÉS, EL MURAL DE LA PLAZA DEL TOSSAL.}
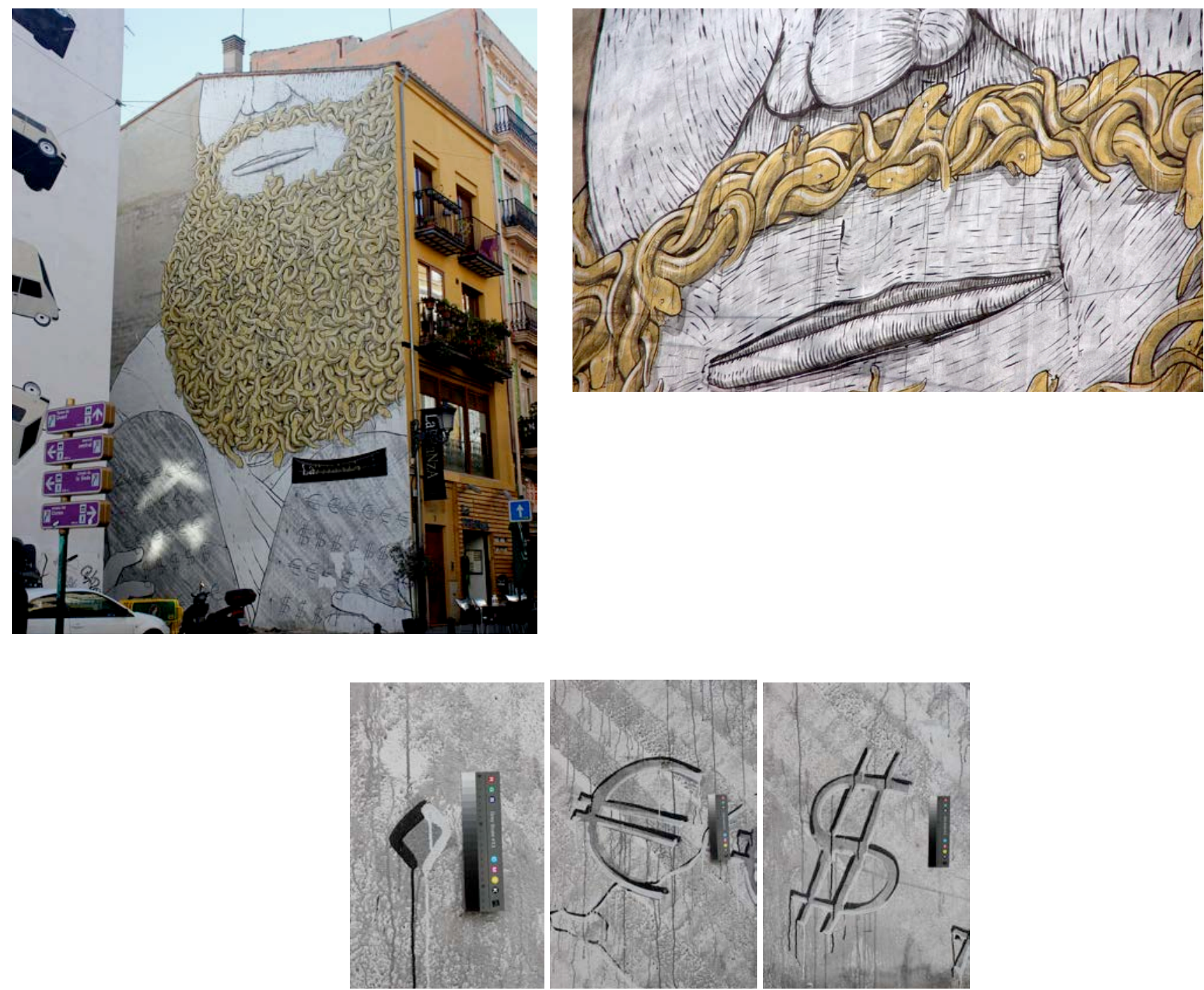

ILUSTRACIÓN 1. Vista general del mural de Blu en 2015.

\footnotetext{
${ }^{3}$ Fatbombers. Entrevista Blu. [Consulta 28/02/2017] Publicado: 1 diciembre 2004. Disponible en: http://www.fatbombers.com/graffiti-vandalism/bl/

${ }^{4}$ DOERNER, M. Los materiales de Pintura y su empleo en el arte. 1998; p. 176
} 


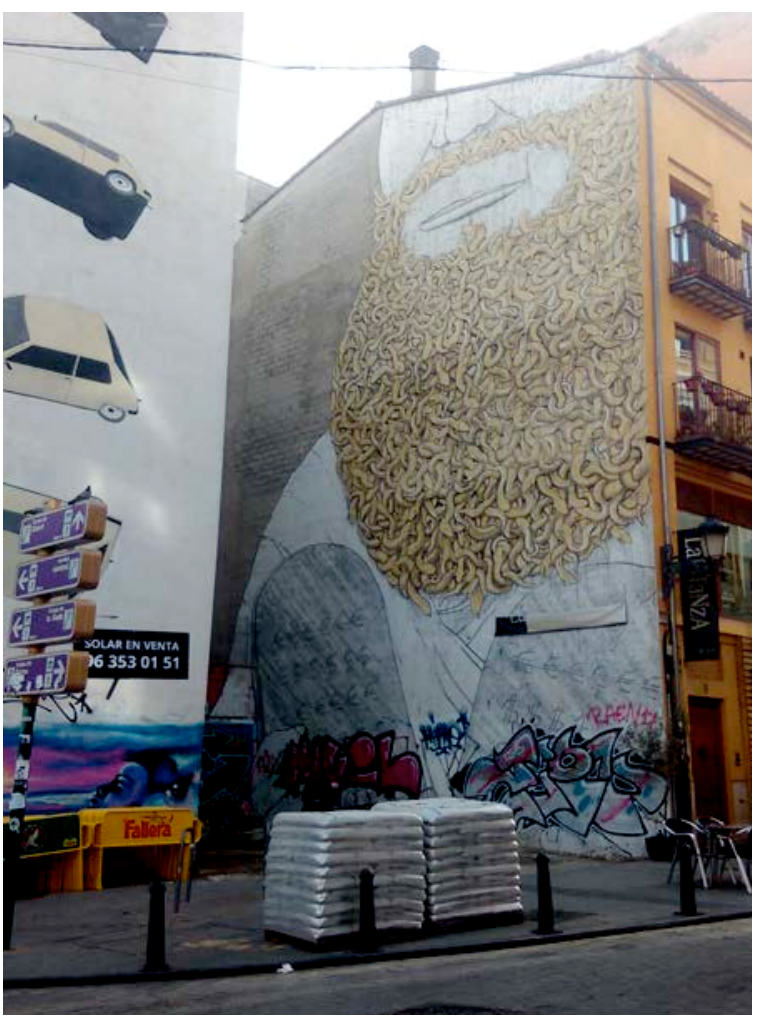

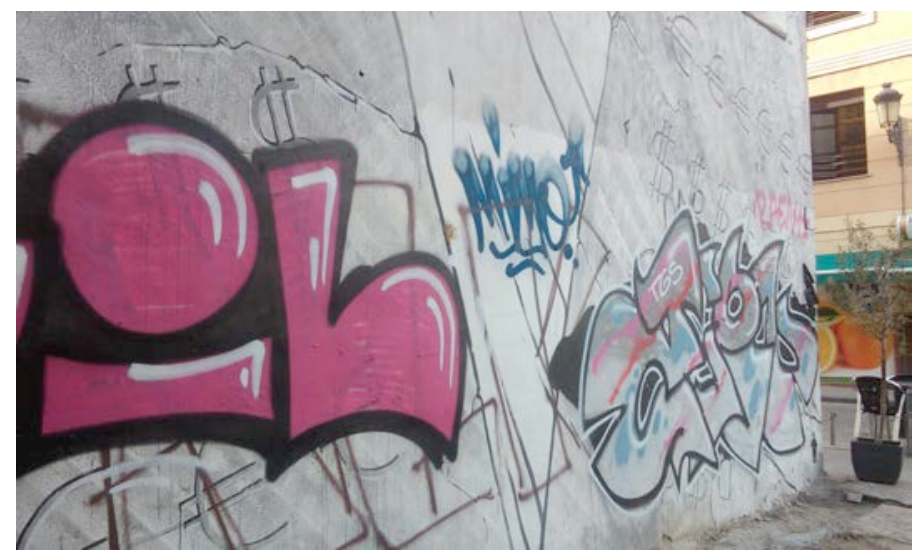

ILUSTRACIÓN. 3. Vista actual de mural de Blu en 2017.

ILUSTRACIÓN. 2. Mural de Blu. Detalles. 2015.
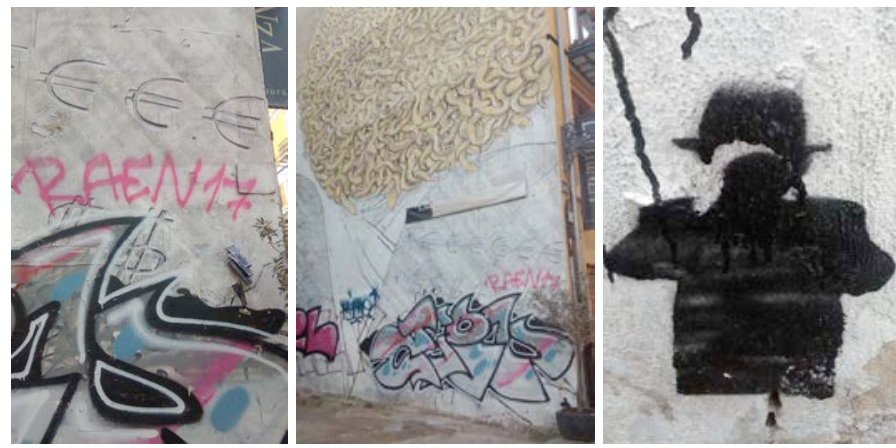

ILUSTRACIÓN. 4. Mural de Blu. Detalles. 2017.

El mural de Moisés, realizado en Julio de 2011, por el artista, nace de la iniciativa de intervenir el espacio público y generar lugares creativos mediante la realización de diversos murales artísticos en las medianeras más visibles de determinadas fincas del barrio del Carmen de Valencia; brota de las jornadas "Comboi a la fresca" organizadas por la asociación AACC -Arquitecturas Colectivas- cuyo propósito radica en la construcción participativa del entorno urbano y donde se aprovecha la oportunidad para construir y/o reciclar un espacio en desuso combinando múltiples enfoques disciplinares.

El artista creó este mural de carácter figurativo en la medianera de la edificación de la Calle Quart, número 5 colindante con la Plaza del Tossal, en el distrito de Ciutat Vella de Valencia $\left(39^{\circ} 28^{\prime} 34.4^{\prime \prime} \mathrm{N} 0^{\circ} 22^{\prime} 49.7^{\prime \prime W}\right)$. Nos encontramos ante un mural ejecutado in situ mediante el uso de materiales propios de un pintor decorador, como: rodillos y pinceles o paletinas anchas, entonado con amarillo, blanco, negro y gris sobre un revestimiento enlucido, tratándose de un mural adaptado a la forma perimetral de la pared y desempeñando su básico principio como es el de ser experimentado en la calle: sus pinturas reinterpretan el lenguaje arquitectónico de los espacios públicos para generar formas nuevas. 
En este espacio, plasma la figura de Moisés, personaje perteneciente a las Sagradas Escrituras de religiones monoteístas que destaca por ser considerado profeta y libertador del pueblo israelita. Blu recurre a los atributos iconográficos del personaje estableciendo un paralelismo metafórico con algunos de sus episodios más representativos dotando a la obra de una carga conceptual concerniente a la economía actual donde recalca y critica el capitalismo: la política y su gestión, así como, la falta de interés de conservación de este barrio proliferando su destrucción y/o el deterioro de los espacios públicos donde se reflejan y se pone de manifiesto la desaprobación sobre la especulación inmobiliaria. Indudablemente, con los años el mural se ha convertido en icono del barrio desempeñando su papel de dialogo con el espectador y con su entorno social y espacial.

Las condiciones de la estructura del edificio sobre el cual asienta la obra es un factor que va a influir decisivamente sobre su estado de conservación. Además, de sufrir los propios agentes de deterioro (intrínsecos de la obra), hay que añadirle los del propio edificio, que afectaran directamente a la pintura mural4; como en este caso, la pérdida de soporte causado por falta de adherencia, bien por exceso o escasez de succión del material base sumado a los movimientos de dilatación y contracción del cemento. La obra se ha visto afectada y deteriorada no solo por patologías sino también por reiterados actos de vandalismo. Estos producen los efectos más perjudiciales aumentando el riesgo de su pérdida e imposibilitando así su recuperación dando como resultado la obstaculización en su lectura. Dichas acciones se concentran en el tercio inferior de la obra, estos actos incluyen no solo la irrupción con pinturas o sprays sino perforaciones o adhesiones de materiales externos como de carteles publicitarios.
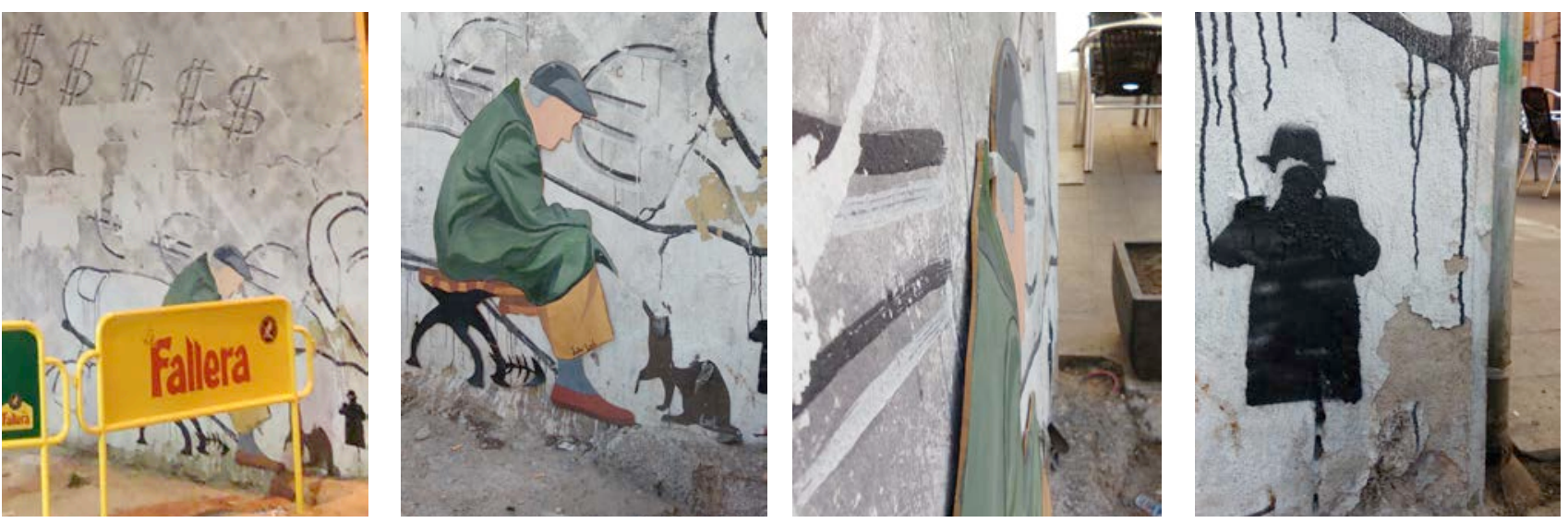

ILUSTRACIÓN. 5. Añadidos ajenos al mural en 2016.

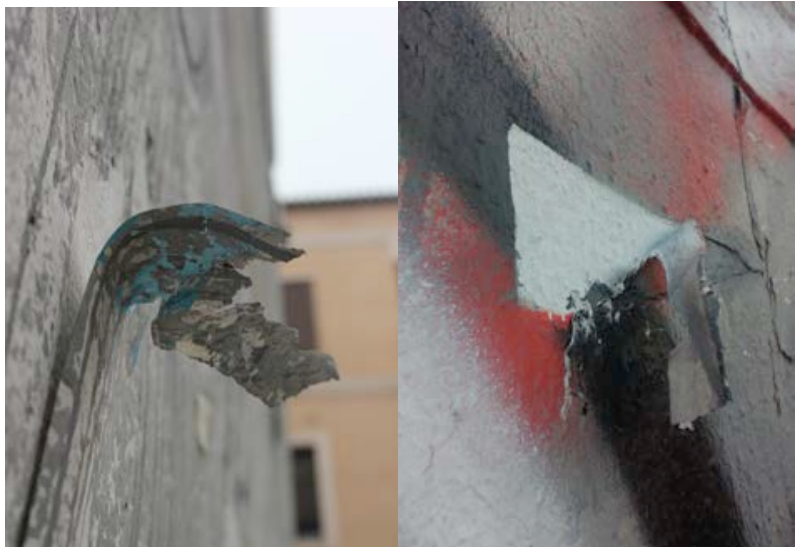

ILUSTRACIÓN. 6. Daños. Desahdesión en 2015 y 2017.

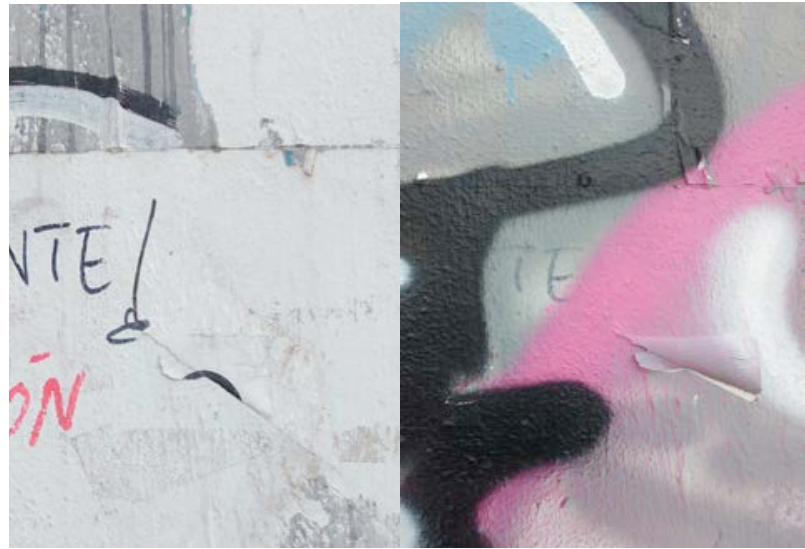

ILUSTRACIÓN. 7. Daños. Tag y graffiti en 2015 y 2017. 

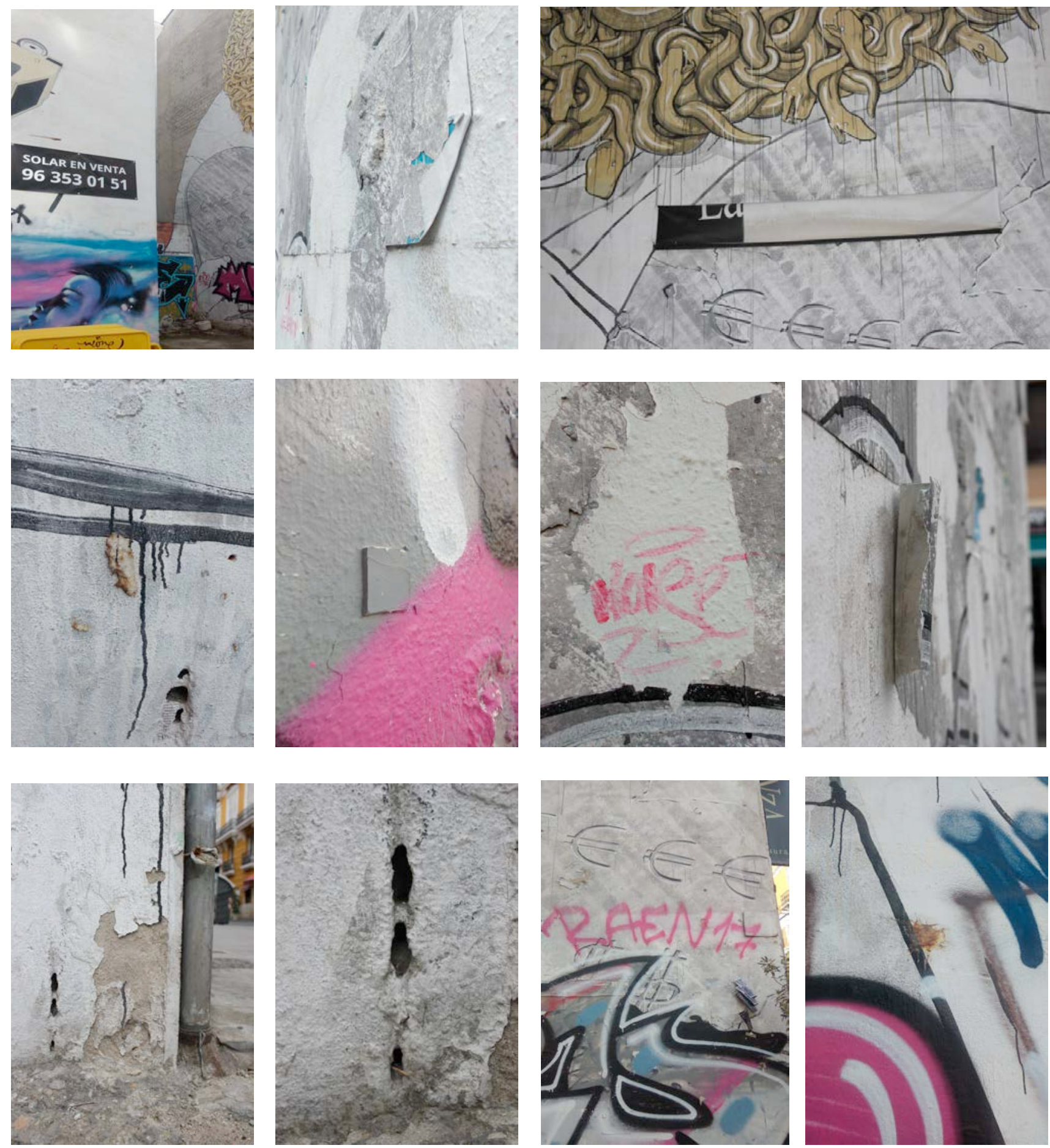

ILUSTRACIÓN. 8. Daños y patologías generales.

Probablemente, un factor de deterioro inminente es el efecto de la intemperie sobre los materiales que se ven afectados por la luz, la humedad, la contaminación, factores biológicos y fenómenos meteorológicos, así mismo por el entorno donde éste se ubica. Patente por ser zona de ocio nocturno, aparcamiento de vehículos y zona de acopio de material, e incluso depósito de escombros y vertedero provocando acumulaciones de suciedad derivadas de orines y heces tanto de animales como de personas. Además la ineludible emisión de humos de vehículos y la extracción de humo de la cocina del puesto ambulante que allí se estaciona, en la semana fallera, a los que hay que sumar el humo expulsado por la falla cercana en su quema. La quema de una falla, es un momento traumático para los edificios colindantes a ésta, las altas temperaturas afectan a los morteros y los materiales arquitectónicos, además en el momento de la combustión, se desprende gran cantidad de anhídrido sulfuroso procedente al igual que los óxidos de nitrógeno de la 
combustión de materiales como el carbón o los hidrocarburos y que tras diferentes procesos y en presencia de humedad forma ácido sulfúrico, que a largo plazo pueden provocar deterioros severos en el mural dando lugar a la alteración heterogénea del color así como desprendimientos pictóricos.
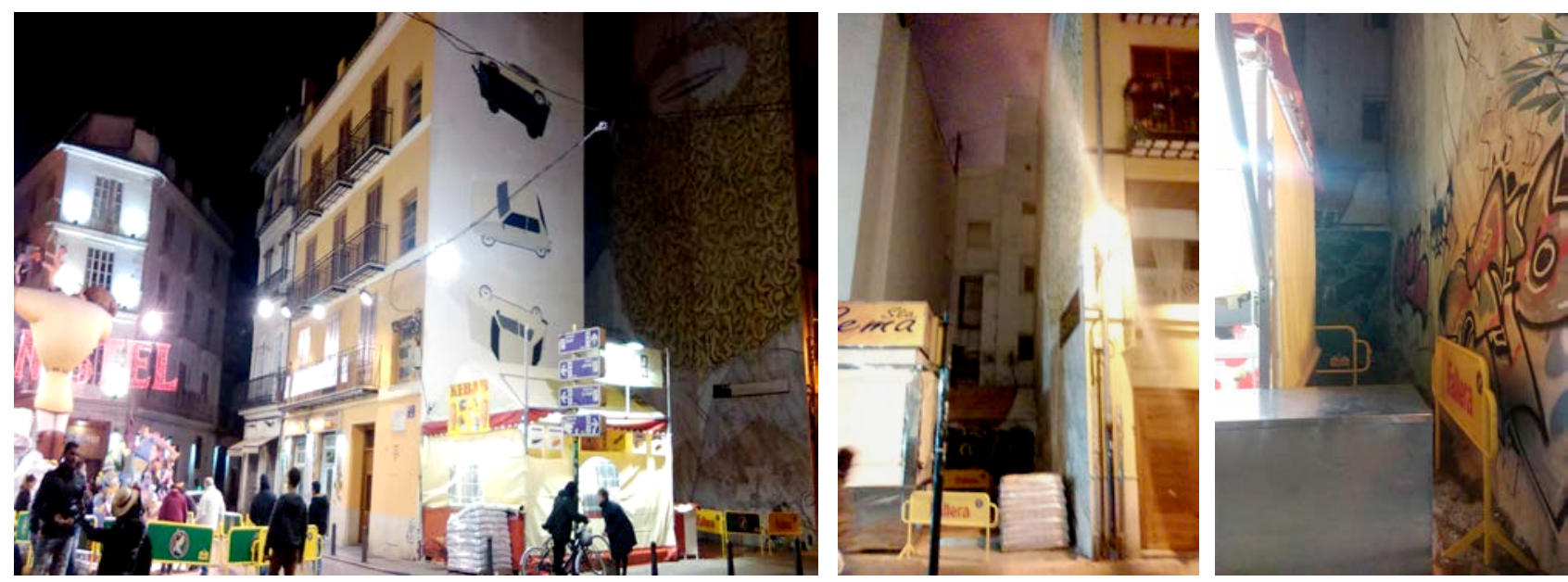

ILUSTRACIÓN. 9. Ubicación de falla y de puesto de comida ambulante durante la semana fallera en 2015, 2016 y 2017.

Otro factor de deterioro, son los causados por daños externos o extrínsecos a la pintura ${ }^{5}$; un graffiti en la mureta contigua donde se sitúa el brazo derecho de la figura de Moisés quedando cubierto casi por completo. La parte frontal derecha se visualizan tags, graffitis, estarcidos, restos de carteles fijados (celo, adhesivo) y perforaciones de tornillos de anclaje. Respecto a la cohesión de los estratos pictóricos, encontramos diferentes niveles de detrimento desde pérdidas de película pictórica, decoloración, pérdida de adhesión hasta desprendimientos del propio muro acompañados de craqueladuras.
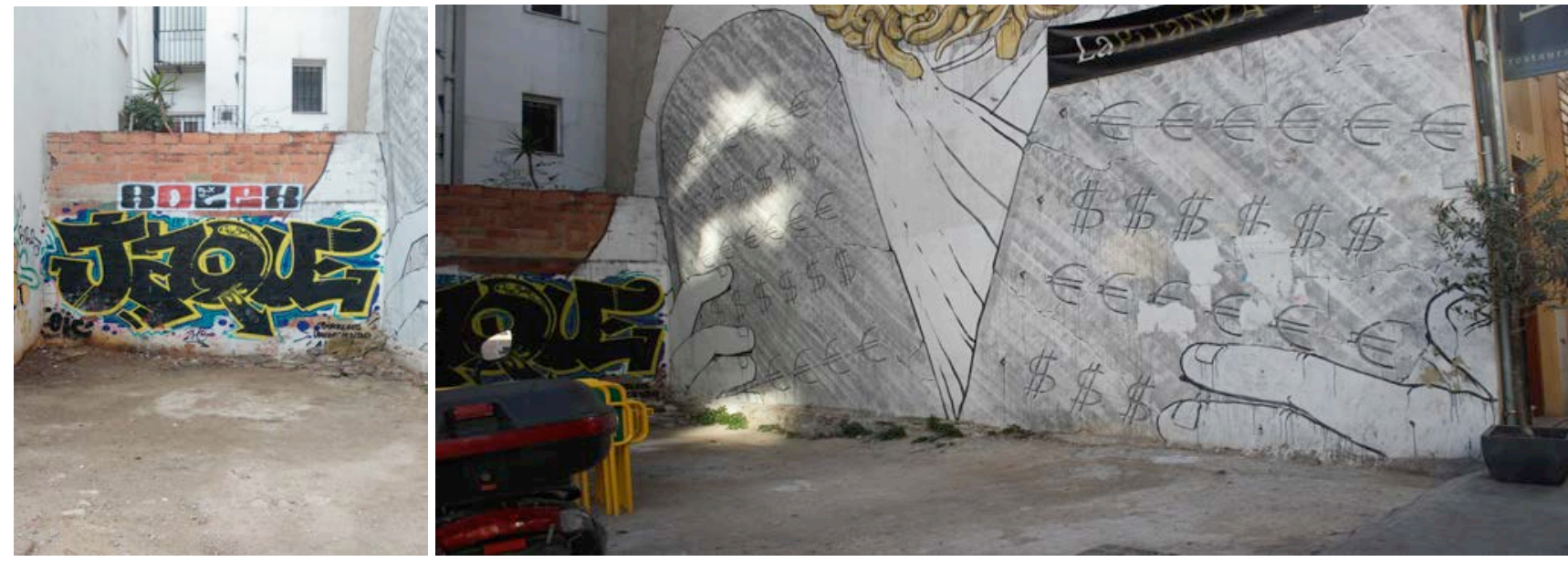

\footnotetext{
${ }^{5}$ Para más información ver: ZALBIDEA, Ma A. Principales causas de alteración de las pinturas murales. Recurso electrónico, 2007.
} 


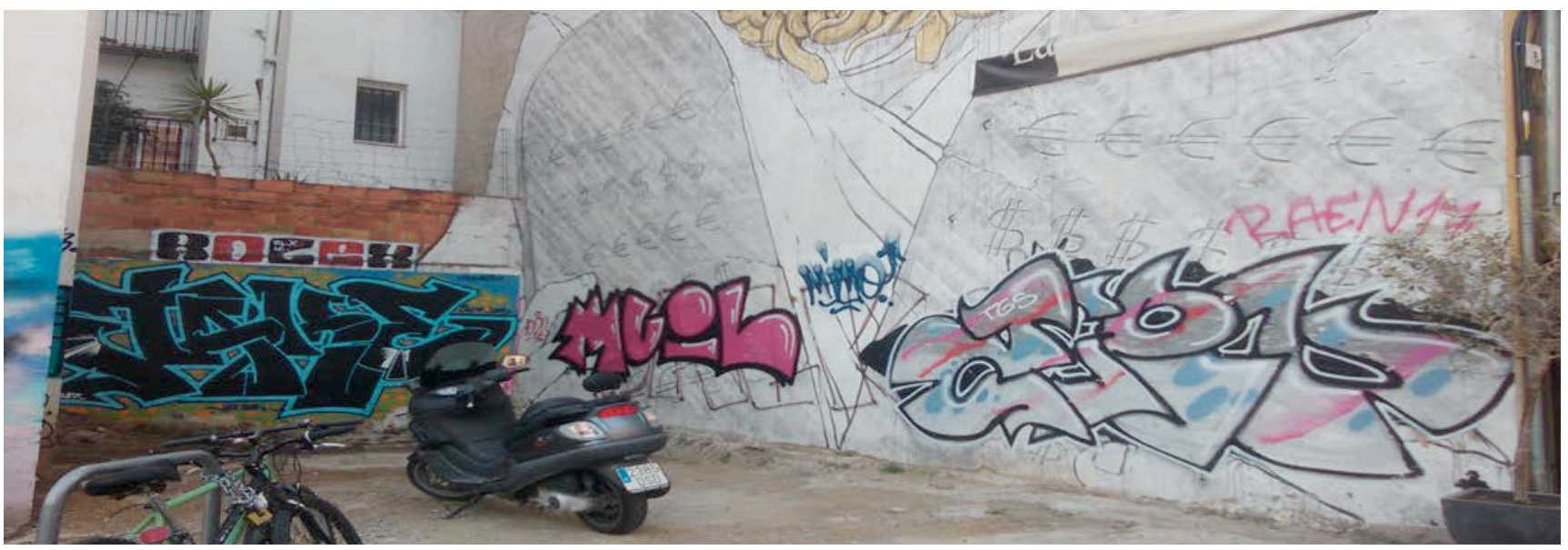

ILUSTRACIÓN. 10. Graffiti en mureta y mural en 2015 y 2017.

Durante el periodo en el que se ha desarrollado el estudio, se realizaron dos tomas termo-higrométricas ${ }^{6}$ al mural para el seguimiento y conocimiento de las condiciones de la obra y su entorno. Donde se concluye que las zonas que presentan mayor rango de humedad son las que se encuentran más próximas y en contacto con la línea propio de un soporte que ha sufrido la acción de la humedad por capilaridad, en este caso causada por la presencia de agua en el terreno y también por la capilaridad de los materiales que permite la subida de agua y que aumenta más, dado la sales disueltas que presenta el terreno, así como las aportadas por los excrementos de animales y orín de personas además de alto nivel freático.

Mediante la extracción de una muestra del mortero se han practicado análisis químicos para determinar tanto el $\mathrm{pH}^{7}$, como la composición cualitativa y cuantitativa de los distintos materiales que conforman el soporte mural. El mortero presente en la obra está formado por la mezcla de un aglomerante y un árido, compuesto por:

$>$ Aglomerante: Carbonato cálcico, Sulfato cálcico y principalmente, arcillas: silicatos de aluminio y óxido de hierro.

> Áridos: Principalmente partículas de sílice y cuarzo, con gravas y puzolanas añadidas (Silicatos y óxidos de hierro).

El estado de conservación de la pintura mural es mayoritariamente bueno. Si bien es cierto que las patologías se concentran en la parte inferior de la obra. La obra se encuentra afectada por la desadhesión del estrato subyacente conformado por carteles dando lugar a la desaparición de película pictórica causados por los daños intrínsecos como los desprendimientos de soporte y estratos pictóricos ocasionados por la escasez o exceso de succión del material base, así como por los efectos de la humedad y la temperatura.

La descohesión y por ende, la pérdida de capa pictórica que presenta la parte inferior y esquina derecha del mural es causada por la humedad filtrada por capilaridad debida a la presencia de agua en el terreno y de sales disueltas en él, además de las aportadas por las deyecciones de animales y personas, así como, por los materiales constitutivos. A su vez, los factores externos de deterioro de la obra son los cometidos por actos vandálicos y deposiciones animales; sin olvidar, el factor contaminación resultado de la combustión de carburantes y la proximidad de fumaradas de extractores y la quema de la falla, que junto a la humedad, producen gases sulfurosos que afectan directamente a la obra.

\footnotetext{
${ }^{6}$ Higrómetro de contacto, marca: HumidCheck ,6-44\%

${ }^{7}$ Resultados obtenidos de la valoración del pH: Superficie pictórica pH. 8, del Mortero pH. 7,5
} 


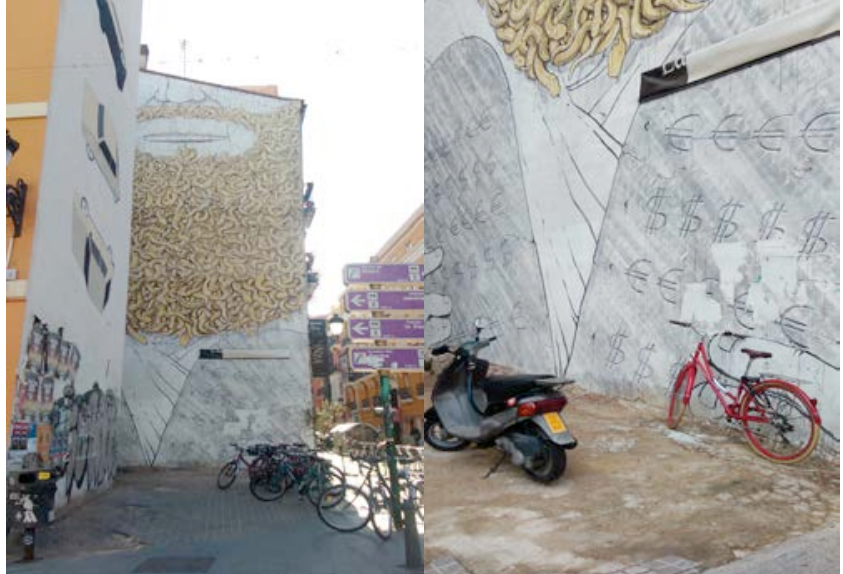

ILUSTRACIÓN. 11. Evolución del mural de Blu Año 2015.

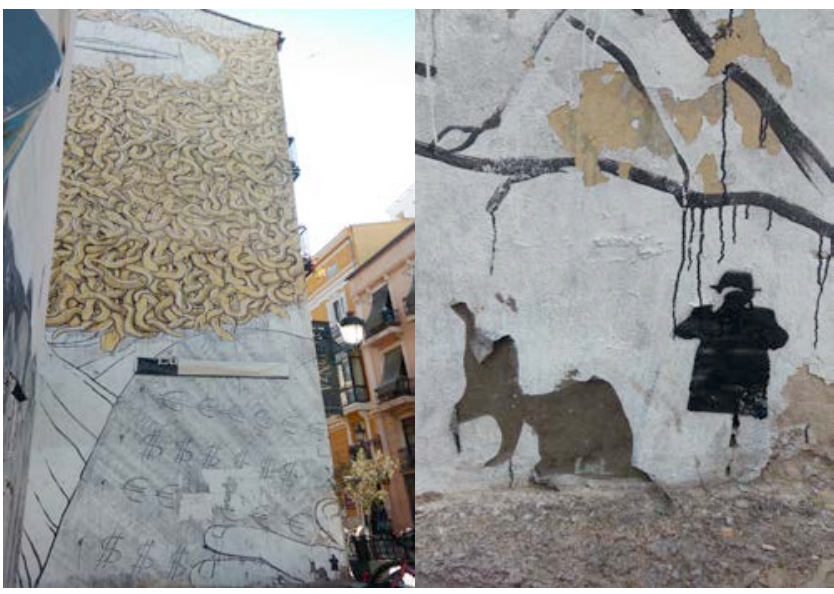

ILUSTRACIÓN. 13. Evolución del mural de Blu. Año 2016.

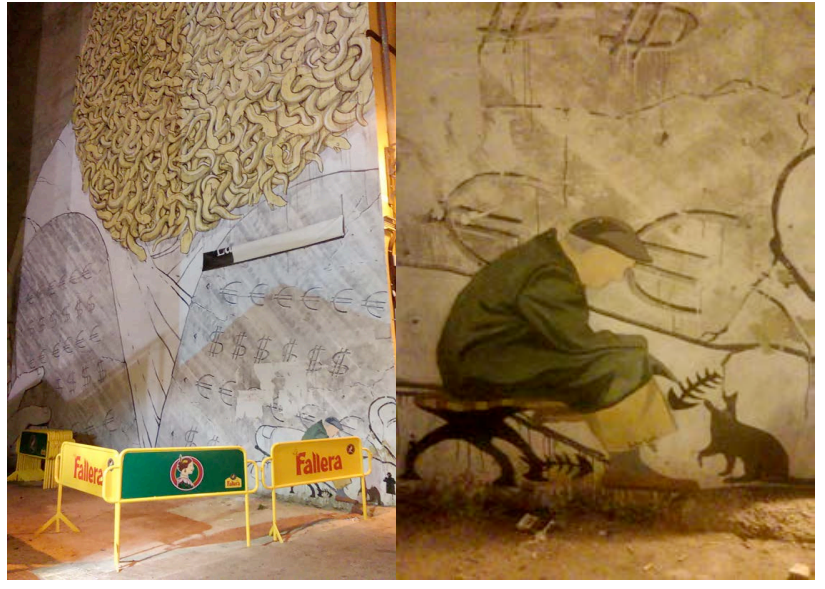

ILUSTRACIÓN. 12. Evolución del mural de Blu Año 2016.

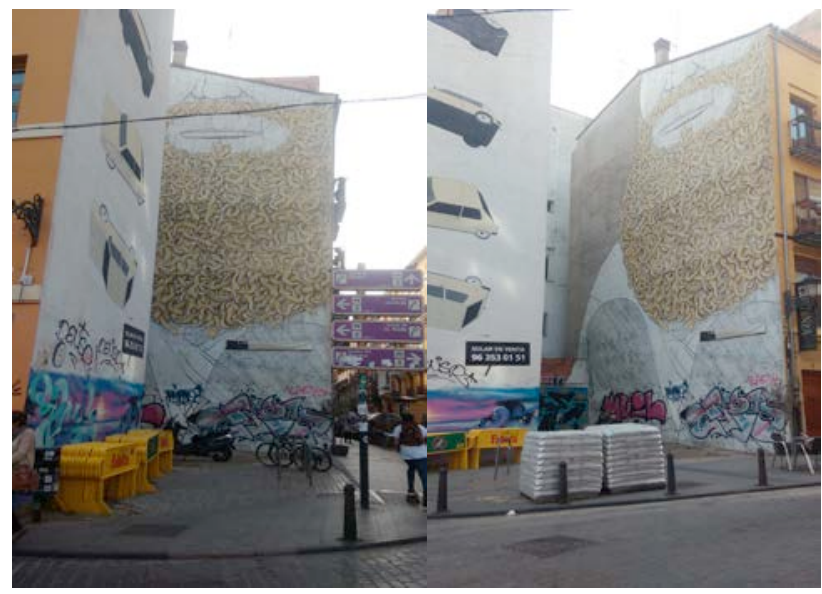

ILUSTRACIÓN. 14. Evolución del mural de Blu. Año 2017.

\section{Conclusiones.}

El mural de Blu en la ciudad de Valencia está dotado de valores de tipo histórico-artístico, social y cultural, llevando consigo implícito, los rasgos que le hacen merecedor de su conservación. Por tanto, se debe preservar la autenticidad y significación de la obra, teniendo en cuenta el inexorable paso del tiempo siendo éste atributo esencial y la disyuntiva principal del arte urbano. Su continuidad en el tiempo la ha transformado en imagen identitaria, pero también vulnerable por una ciudad que se transforma por sus intereses.

Dicho lo cual y tras una evaluación del estado actual y gestión de riesgos mediante la realización de exámenes técnicos y químicos de soporte y materiales constituyentes realizados con el propósito de asegurar su salvaguarda, con el fin de conseguir su estabilidad y detectar futuras patologías e impedir la degradación e incluso pérdida total de la obra.

Por otra parte, el papel de la sociedad es concluyente para su trascendencia ya que se convierte en la beneficiaria y se considera como principal vía la salvaguarda documental, puesto que la obra no nace con la finalidad de ser inmortal y puede desaparecer en cualquier momento; dicho lo anterior y gracias a los recursos tecnológicos que disponemos el registro de documentación fotográfica es crucial y necesaria para su conservación y difusión.

El carácter efímero que se le ha adjudicado arbitrariamente a estos murales urbanos no es más que un arraigo social generalizado y forjado para reforzar la disyuntiva en la parcelación de arte-museo y arte-calle; o de manera análoga, la autonomía del museo. 
Al estar la obra emplazada en la calle es latente la finalidad de interactuar con su entorno, su contexto y con el espectador, así pues, salvo en condiciones de pérdidas matéricas desmesuradas nunca deberá ser extraída de su lugar de origen para su venta o exposición museística sin previa autorización del artista.

\section{FUENTES REFERENCIALES.}

AAVV. Mural Street Art Conservation no 3. En: Revista electrónica de conservación de Street Art. GE-ICC. Grupo Español del IIC (International Institute for Conservation of Historic and Artistic Works) Publicado en Abril de 2016. ISSN2444-9423. Disponible en: https://issuu.com/observatoriodearteurbano/docs/mural_3

DEL PINO DÍAZ, C. Pintura mural conservación y restauración. Madrid. Ed: Dossat-2000 S.L., 2011. ISBN: 9788489656888

DOERNER, M. Los materiales de Pintura y su empleo en el arte. Madrid. Ed: Reverte, 1998. ISBN: 9788429114232

MANCO, T; “The 10 best street art Works". En: The Guardian [27/02/2017] Publicado: 6 agosto 2011. Disponible en:

https://www.theguardian.com/culture/gallery/2011/aug/07/art

Fatbombers. Entrevista Blu. [28/02/2017] Publicado: 1/12/2004. Disponible en: http://www.fatbombers.com/graffiti-vandalism/bl/

MÖSKEN, A; “Wandbild an Cuvrybrache übermalt Schwarz ist das neue Blu” Berliner zeitung.de [02/02/2017].Publicado 12/12/2014. Disponible en: http://www.berliner-zeitung.de/berlin/wandbild-an-cuvrybrache-uebermalt-schwarz-ist-das-neue-blu-504004

SMARGIASSI, M; "Blu cancella tutti i suoi murales; “No alla street art privatizzata” Reppublica.it. Bolonia [02/02/2017] Publicado 12/03/2016. Disponible en: http://bologna.repubblica.it/cronaca/2016/03/12/news/bologna_graffiti-135303806/\#13;

ZALBIDEA, Mạ A. Principales causas de alteración de las pinturas murales. Universitat Politècnica de València, 2007. ISSN 9788483631164. 